\title{
Co-creating narratives for WEF nexus governance: a Quantitative Story-Telling case study in the Canary Islands
}

\author{
Violeta Cabello $^{1} \cdot$ David Romero $^{2} \cdot$ Ana Musicki $^{3} \cdot$ Ângela Guimarães Pereira $^{2} \odot \cdot$ Baltasar Peñate $^{3}$
}

Received: 17 July 2020 / Accepted: 15 February 2021 / Published online: 31 March 2021

(C) The Author(s) 2021

\begin{abstract}
The literature on the water-energy-food nexus has repeatedly signaled the need for transdisciplinary approaches capable of weaving the plurality of knowledge bodies involved in the governance of different resources. To fill this gap, Quantitative Story-Telling (QST) has been proposed as a science for adaptive governance approach that aims at fostering pluralistic and reflexive research processes to overcome narrow framings of water, energy, and food policies as independent domains. Yet, there are few practical applications of QST and most run on a pan-European scale. In this paper, we apply the theory of QST through a practical case study regarding non-conventional water sources as an innovation for water and agricultural governance in the Canary Islands. We present the methods mixed to mobilize different types of knowledge and analyze interconnections between water, energy, and food supply. First, we map and interview relevant knowledge holders to elicit narratives about the current and future roles of alternative water resources in the arid Canarian context. Second, we run a quantitative diagnosis of nexus interconnections related to the use of these resources for irrigation. This analysis provides feedback to the narratives in terms of constraints and uncertainties that might hamper the expectations posed on this innovation. Thirdly, the mixed analysis is used as fuel for discussion in participatory narrative assessment workshops. Our experimental QST process succeeded in co-creating new knowledge regarding the water-energy-food nexus while addressing some relational and epistemological uncertainties in the development of alternative water resources. Yet, the extent to which mainstream socio-technical imaginaries surrounding this innovation were transformed was rather limited. We conclude that the potential of QST within sustainability place-based research resides on its capacity to: (a) bridge different sources of knowledge, including local knowledge; (b) combine both qualitative and quantitative information regarding the sustainable use of local resources, and (c) co-create narratives on desirable and viable socio-technical pathways. Open questions remain as to how to effectively mobilize radically diverse knowledge systems in complex analytical exercises where everyone feels safe to participate.
\end{abstract}

Keywords Quantitative Story-Telling · Co-creation · Narratives · Water-energy-food nexus · Alternative water resources

\section{Introduction}

The water-energy-food nexus ${ }^{1}$ concept has spread as a fresh approach to the so-called 'wicked problems' in sustainability sciences, which are characterized by complex-

Handled by Rosemary Hill, CSIRO Land and Water Flagship Cairns, Queensland, Australia.

Ângela Guimarães Pereira

angela.pereira@ec.europa.eu

Universitat Autònoma de Barcelona, Barcelona, Spain

2 Joint Research Center of the European Commission, Ispra, Italy

3 Instituto Tecnológico de Canarias, Las Palmas, Spain ity, uncertainty, and multiple, often contested, values (Rittel and Webber 1973; Harwood 2018). It draws attention to the interdependencies between the management of different resources and raises questions on the limits of singleresource governance models like Integrated Water Resource Management (Pahl-Wostl 2019). Furthermore, the nexus is increasingly seen as a useful platform to implement the UN Sustainable Development Goals linked to food, water,

\footnotetext{
${ }^{1}$ From now on referred as 'the nexus'.
} 
land, and energy (Stephan et al. 2018; Pahl-Wostl 2019). Yet, there are significant analytical and operational challenges for the nexus to contribute to such ambitions. As an analytical concept, the nexus invites interdisciplinary communication between complex system methods capable of quantifying relations between resources (Zhang et al. 2018) and policy analysis addressing coherence and integration instruments (Venghaus and Hake 2018). At an operational level, the nexus calls for transdisciplinary collaboration with those actors involved in the management of water, food, and energy (Mohtar and Daher 2016). In this regard, gaps have been identified in social-science-driven interdisciplinary nexus assessments (Albrecht et al. 2018) and in how diverse knowledge systems can be weaved in nexus research (Hoolohan et al. 2018).

Quantitative Story-Telling (QST) has been recently proposed as a science for adaptive governance approach that aims for 'quality checks' in the narratives used to promote policies and innovations that are relevant for the nexus (Saltelli and Giampietro 2017; Matthews et al. 2017). Quality in QST is appraised according to criteria of "plausibility" of those narratives when considering constraints and tradeoffs across nexus dimensions (Renner and Giampietro 2020). The operationalization of these criteria in analytical terms is open to mixed-method developments tailored to particular problems and contexts, with three common denominators. First, QST uses narratives as analytical tools to elucidate the plurality of views about analyzed problems together with their implicit assumptions and uncertainties. Second, narrative analysis is combined with multi-scale quantifications of resource nexus interconnections for the above-mentioned quality checks. Third, QST engages stake and knowledge holders in the research process as the 'extended peer community' that is both affected by and affecting nexus-related problems (Healy 1999).

A well-known sustainability problem related to the nexus is the cross-scale feedback between water scarcity, driven by decades of overdrafting freshwater resources in many Southern regions, and food security granted by those resources in Northern importing countries (Hogeboom et al. 2020). The growing gap between water availability and demand has prompted the exploitation of non-conventional water resources, namely desalination and wastewater reuse (Gude 2017; Monterrey-Viña et al. 2020). However, the viability of these alternative water resources (AWR) to address irrigation problems has repeatedly been called into question (Von Medeazza 2005). On one hand, the fact that the energy dependencies of AWR cannot be afforded by all farming systems raises equity questions (McEvoy and Wilder 2012). On the other hand, the role these resources should play within the water management systems in which they are promoted is often ambiguously defined and lacks proper monitoring (Jones et al. 2019).
In this article, we present the first application of QST to a place-based case study on AWR as an innovation for water and agricultural governance in the Canary Islands Archipelago (Spain). This isolated and arid territory pioneered the development of AWR decades ago (SerranoTovar et al. 2019). As mentioned above, the QST hypothesis is that focusing on the quality of narratives requires welcoming divergent perspectives, unsettling assumptions, making uncertainties explicit and putting constraints and contradictions at the center of the research process. In this method paper, we take a reflexive stance (Popa et al. 2015) to describe how we applied these principles in practice. First, we introduce our understanding of QST as an approach for the co-creation of knowledge about the WEF nexus and discuss the different applications of narrative inquiry in it. Then, we describe stepwise how we connected several methods to mobilize a plurality of nexus-related knowledge systems, including those from the interdisciplinary plethora of authors, and to create interactions among them. We conclude with some reflections on the outcomes of the process and what insights they provide to the practice of QST and, by extension, to WEF nexus and sustainability research.

\section{Quantitative Story-Telling for place-based nexus knowledge co-creation}

The original idea of Quantitative Story-Telling was proposed in the European project Moving Towards Adaptive Governance In Complexity as an alternative to mainstream evidence-based policy (Saltelli and Giampietro 2017). Drawing philosophically from post-normal science ideas on irreducible uncertainty, plural values, and quality of knowledge (Funtowicz and Ravetz 1993), the aim of QST is to open up the science for policy process in at least two ways. First, by incorporating different narratives when framing the problem, especially those from other nexus policy domains (Kovacic and Di Felice 2019; Voelker et al. 2019). Second, by applying multi-scale integrated analysis of resource nexus interconnections to systematically search for relevant constraints to proposed policy pathways (Serrano-Tovar et al. 2019; Cabello et al. 2019).

When applied to innovations, QST follows Science and Technology Studies' concerns for how certain technologies come to be promoted as desirable policy solutions, often as means to avoid solving inconsistencies with other governance domains (Jasanoff et al. 2001). The nexus concept thus helps to signal connections between policy incoherencies and innovations, and between those and the specific contexts where innovations are deployed while adding resource nexus interdependencies (Cabello et al. 2019). Here, QST asks what socio-technical imaginaries are privileged throughout the policy-innovation cycle and what do alternative 


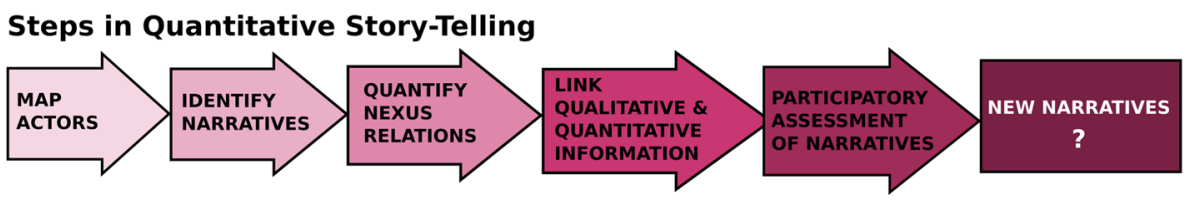

Methods applied and outputs obtained

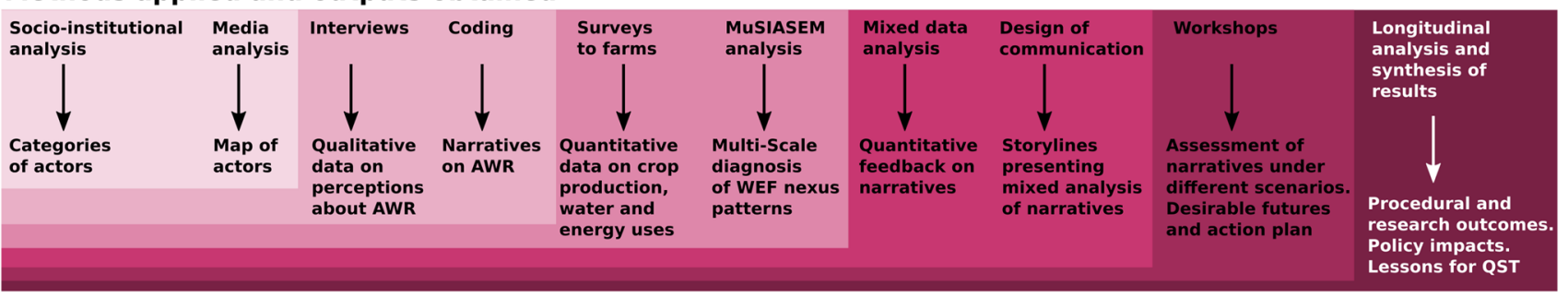

Fig. 1 Overview of the QST process, methods applied, and outputs/outcomes obtained in this research

narratives bring in terms of emerging contradictions, constraints, or uncertainties (Jasanoff and Kim 2015).

Our QST's co-creation logic-related quality aspects to the mobilization of different knowledge systems (local, scientific, technical, and political) to then appraise existing narratives about AWR and prompt new imaginaries. Two guiding principles are distilled from this positioning. First, pluralism as the inclusion of 'multiple ways of knowing and doing' (Norström et al. 2020), which is generally assumed to enrich the problem framing and the knowledge co-creation outcomes. Second, reflexivity as the explicit questioning of underlying values and normative assumptions that helps new meaning and shared understandings to emerge (Popa et al. 2015). Together, these principles when applied to place-based research raise the question of how to generate interactive spaces where pre-established assumptions can be challenged and critical reflections engendered in a manner that is salient, legitimate, and credible for participants (Cash et al. 2003; Bremmer et al. 2017). The way QST generates these interactive spaces is with the use of narratives.

Following Voelker et al. (2019), narratives describe a sequential ordering of events constituting particular temporal and spatial structures and establishing a set of subject positions with particular rationales, often together with a causal relationship between a problem and a solution. The analysis of narratives in policy discourses has a certain tradition within sustainability sciences (Hajer 1995). A common application is the analysis of how certain narratives become sanctioned within the policy process, while others are discredited (Molle 2008; Cabello et al. 2018). QST echoes this perspective usually by departing from a text-based analysis of institutional narratives about the 'why, what and how' of European policy instruments and innovations (Kovacic and Di Felice 2019).

Alternatively, narratives can be analyzed through public engagement methods. First, interviews have been applied to access the stories people use to understand and create meaning around their experience with social-ecological phenomena (Marschütz et al. 2020). In this vein, narratives become a tool to engage with plural perspectives about the role, the expectations and the challenges of AWR, giving voice to under-represented positions (Bremer et al. 2017). Furthermore, narratives can also be understood as 'knowing in action' (Paschen and Ison 2014), that is, as a social process whereby knowledge is produced in the act of narrating an experience. Narrative inquiry thereby becomes a method to study the emergence of knowledge as part of social contexts and interactions (Paschen and Ison 2014, pp. 1084). This performative view of narratives is particularly well suited to analyze the transformation of knowledge in participatory spaces where meaning is re-negotiated and cocreated through information exchange and dialogue (Cabello et al. 2018). It also attends to aspects of positionality in such interactions, which we find crucial when engaging actors with unequal stakes in the development of AWR. In words of Paschen and Ison (2014, p. 1986), a reflexive narrative approach attends to questions of 'who is speaking from where, to whom and for what purpose'.

Altogether, we argue that this methodological pluralism in narrative research aids the application of QST to placebased research on the implications of nexus interconnections for the governance of AWR.

\section{Operationalizing QST}

In our case study, we operationalized and connected different methods in the QST process (Fig. 1) as follows. Two study areas were selected in different islands of the Canary Archipelago. The first area is the region of the Southeast of Gran Canaria, an agricultural area with a long trajectory in the use of AWR. Here, we analyzed narratives about the experiences 
Table 1 Resulting typology and number of engaged actors

\begin{tabular}{|c|c|c|c|c|c|c|}
\hline \multirow[t]{2}{*}{ General category } & \multirow{2}{*}{$\begin{array}{l}\text { Type of institution or organi- } \\
\text { sation }\end{array}$} & \multirow[t]{2}{*}{ Nexus knowledge area } & \multicolumn{2}{|l|}{ Interviews } & \multicolumn{2}{|l|}{ Workshops } \\
\hline & & & Gran Canaria & Tenerife & Gran Canaria & $\overline{\text { Tenerife }}$ \\
\hline \multirow{6}{*}{$\begin{array}{l}\text { Public administration and } \\
\text { nexus planning bodies }\end{array}$} & Canarian Government & All & 2 & & & \\
\hline & Insular Governmental bodies & Water & 1 & 2 & 3 & 3 \\
\hline & & Agriculture & 2 & 1 & 4 & 4 \\
\hline & & Energy & & & 1 & \\
\hline & & Environment & & & 1 & \\
\hline & Municipalities & All & 1 & 1 & 3 & 2 \\
\hline \multirow{6}{*}{$\begin{array}{l}\mathrm{R} \& \mathrm{D} \\
\text { organisations }\end{array}$} & Universities & Agronomy & 1 & & 1 & 1 \\
\hline & & Social sciences & 1 & & 2 & 1 \\
\hline & & Environmental Sc & & 2 & & \\
\hline & Governmental R\&D centers & Water, energy engineering & 1 & & 5 & 3 \\
\hline & & Agronomy & 1 & & 1 & 3 \\
\hline & Private $R \& D$ centers & Water & 1 & & & \\
\hline \multirow[t]{3}{*}{ Agricultural organisations } & Individual farmers & Agriculture & 1 & & 2 & \\
\hline & Unions & & 1 & & 1 & 3 \\
\hline & Cooperatives and companies & & & 2 & 1 & 4 \\
\hline \multirow{3}{*}{$\begin{array}{l}\text { Water management organisa- } \\
\text { tions and consultants }\end{array}$} & AWR producers & Water & 1 & 1 & 1 & 2 \\
\hline & $\begin{array}{l}\text { Irrigation communities and } \\
\text { private freshwater owners }\end{array}$ & & & 1 & 2 & \\
\hline & AWR consultants & & & 1 & & \\
\hline \multirow[t]{5}{*}{ Civil society } & Environmental organisations & Environment & 1 & 1 & 2 & \\
\hline & $\begin{array}{l}\text { Food sovereignty and local } \\
\text { associations }\end{array}$ & Agriculture and environment & & & 1 & 1 \\
\hline & Undergraduates & & & & & 7 \\
\hline & & Total per island & 11 & 12 & 31 & 34 \\
\hline & & Total regional & 4 & & & \\
\hline
\end{tabular}

managing these resources and the challenges ahead. The second study area focused on a new project of reclaimed water for agricultural use in the Valle Guerra region, Northeast Tenerife. When initiating this study, a tertiary treatment plant was launched, but the distribution network was still under construction. Therefore, farmers were relying exclusively on freshwater resources. Contrary to the Gran Canaria case, this study provided insights into the expectations and conflicts raised when an innovation is initially implemented. Both agricultural areas produce a variety of irrigated crops mostly for exportation (65-80\% of annual production) but also for local markets and self-consumption.

This section covers the different stages and methods of our QST process as presented in Fig. 1. We only include mentions to relevant results to reflect on the quality of the process with regards to our methodological objectives.

\section{Socio-institutional analysis and stakeholders map}

Our QST process kicked off with a socio-institutional analysis that enabled a shared framing of the issue among researchers with different backgrounds and a general contextualization within the social, technical, and regulatory context of AWR in the Canaries. Building upon Corral-Quintana et al. (2016), the methodology at this stage combined the analysis of normative documents, websites of institutions and organisations, local gray, and scientific literature regarding water, energy, and agricultural governance in the region. In addition, this process assisted in mapping the relevant categories of actors to engage.

Table 1 presents the actors by categories. In the first stage, a broad categorization of actors was made according to their social-institutional roles, responsibilities and decision capacity within the Canarian context (general category in Table 1). As the analysis advanced, the different institutions and organisations identified were placed into the respective categories. Third, to identify representatives of each of these groups, we searched online social networks and main regional newspapers from 2017 to 2019. Individuals actively speaking or involved in the topics of agriculture, water, and energy were identified, obtaining an initial list of 50 actors. This list was filtered to a balanced sample of 30 actors actively speaking about AWR in relation with water and agriculture, and to a lesser extent 
with energy (the energy dimension was less frequently discussed in the media).

\section{Identification of narratives}

\section{Interviews}

The interviews served the purpose of initiating the engagement process through a one-to-one conversation while eliciting narratives with regards to the past, present, and future of AWR in the study areas. An interview guide was collaboratively prepared by all members of the research team (see Online Appendix). We tried to widen the scope of analysis from the specific technical challenges AWR are facing to the roles they play in the islands' environmental, socioeconomic, and institutional contexts. For this reason, the interviews commenced by asking about their views on the situation of water resources and the agricultural sector and about the purpose of AWR within this context. To improve our understanding of the network of actors and to identify actors to engage in the final workshop, we included questions on the interviewee relation with AWR and on the actors involved in both their development and governance. We further inquired about the current challenges and the future expectations. Finally, we introduced the nexus concept and asked about its potential usefulness for their daily actives and more in general for AWR governance.

Actors were contacted by phone and email and interview sessions were scheduled throughout January and February 2019. The interviews were semi-structured and conducted in Spanish by two researchers of the team, both Canarian and with different backgrounds in sociology and agronomy. Out of the 30 contacted actors, a total of 27 were finally interviewed (Table 1). In Gran Canaria, 7 interviewees represented expert knowledge from either public authorities or research organisations, with agricultural backgrounds more represented than water knowledge. On the other hand, in Tenerife, there was a stronger focus on water backgrounds and a larger representation of water and agricultural management organisations.

Civil society and individual farmers were under-represented in the sample of actors interviewed on both islands. This underrepresentation can be considered a limitation of our methodological procedure, because those groups have lower presence in the mainstream regional media. Thus, a more exhaustive search is needed using other sources, such as alternative, non-official, or very local media. Finally, it is noteworthy that only 3 of our interviewees were women, neither of them from governmental bodies, suggesting that this group is under-represented both in the media and in the institutional context.

\section{Interview coding}

In terms of the analysis, our first step was to distil the narratives from interviewed actors through an iterative coding of interview transcripts. A coding framework was developed connecting different categorizations of narratives (see Table A.1 in the Online Appendix). The first and most important analytical criterion was the way interviewees storied causality relations around AWR. For this purpose, we built upon Felt and Kommission (2007) to distinguish between justification narratives (why were/are AWR pertinent innovations in the study areas? What challenges do they face?), normative narratives (what should be done?), and explanation narratives (how should challenges be addressed?). These main questions linked to each type of narrative were answered following the pre-designed coding framework, associating specific actors' quotes to each code. For instance, key codes for justification narratives are 'social-ecological perception', 'causes', 'benefits', and 'problems'; for normative narratives: 'solution', 'role'; and for explanation: 'action' and 'target'. In the next step, we built the narratives analyzing the narrated causes-effects; how causes and benefits are related; what are the concerns at the moment; and what is the role of particular measures, targets, and policy instruments. Following this analysis, we arrive at a set of narratives, which do not represent specifically the vision of the interviewed person, but the standpoint of several actors as exposed in the typology of Table 1. It is worth noting that actors might not align across all narratives, but rather follow different causal avenues from the problems they perceive to particular solutions.

As a second analytical dimension, we focus on uncertainties surrounding the stories about causality. For this, we built upon Brugnach's et al. (2008) relational uncertainty framework. We systematically coded as ambiguities the claims that sustained divergent positions in the identified narratives. We also analyzed epistemological uncertainties as claims referring to insufficient information or uncertainties about a particular issue and used as input for decision making.

Finally, we selected the most representative narratives to be considered in subsequent steps of the QST process (see list in the Online Appendix). By representative, we mean narratives claimed from more than one actor. In fact, those narratives defended by only two actors were coded as 'underrepresented' as compared to 'mainstream' narratives were more interviewees aligned. We only selected one narrative upholded by a single actor in Tenerife. The reason behind this exception is that this actor contested the main justification provided by AWR promoters from an important power position in the network of actors. Therefore, its influence as a contested narrative was high.

In general terms, the analysis revealed a strong convergence among most interviewees on the defense of AWR as a means to guarantee water availability and security in the 
Canaries. In the case of Gran Canaria, most actors highlighted the multiple benefits of AWR whereas the farmer and agronomic experts discussed new problems and risks associated with their quality. We observed strong concerns about the situation of the agricultural sector connected to proposals for making AWR accessible to small and rural farming systems producing for local markets. On the other hand, in Tenerife, we found critical perspectives of the role of AWR within the economic model of the island, contesting mainstream justifications. We also observed divergent positions with regards to farmers' acceptance of the new resources. Considering these results, we decided to focus the final workshops on exploring those aspects with divergent opinions on one hand, and the uncertainties surrounding the expectations on future uses of AWR on the other hand. Before that, the identified narratives were contrasted with a quantitative analysis of nexus interconnections.

\section{Quantitative analysis of nexus networks}

Quantitative analysis within QST serves the purpose of generating pertinent feedback to previously identified narratives in terms of: (i) a system analysis that contextualizes the problem, (ii) exploration of ambiguities and divergent positions with available quantitative data; (iii) identification of key constraints to expected solutions or pathways derived from trade-offs across WEF nexus dimensions, and (iv) identification of key epistemological uncertainties with regards to existing data and evidence. The quantitative engine of QST is the Multi-Scale Integrated Analysis of Societal and Ecosystem Metabolism-MuSIASEM (Giampietro and Bukkens 2014) and its recent developments to nexus networks (Cabello et al. 2019; Serrano-Tovar et al. 2019). In a nutshell, MuSIASEM applies systems thinking to analyze relations between patterns of production and consumption of water, food, energy, and other resources. In addition, it explores relations between societal and environmental variables across scales.

In our research, MuSIASEM was applied to diagnose how AWR were used within the common pool of water resources, by what type of farming systems and at what energy and monetary cost in the study areas. To analyze such patterns of water use - food production - energy use, data were gathered through field surveys to a stratified sample of farms in each study area (31 in Gran Canaria and 37 in Tenerife) and complemented with secondary data sources. Among other agronomic variables, farmers were asked about their production systems (crops, technology, inputs, production, and markets) and water management practices (sources, suppliers, prices). The survey in Tenerife included explicit questions about the acceptance of the new reclaimed water resources. Secondary data sources were used to complete gaps in the surveys, to analyze the status of groundwater bodies and the energy costs of the different water resources.

Since the focus of this paper is on the analysis of narratives, a summary of the design of the nexus network and of the data management process is provided in the Appendix. Further information can be found in the MAGIC project deliverable (Cabello et al. 2020). In the next section, we explain how we analyzed quantitative data to provide feedback onto the narratives.

\section{Connecting qualitative and quantitative analysis}

The second analytical step was explicitly framed within the final deliberative workshops. That is, the contents and formats of the analysis were designed as a means to set the scene for an exercise of collective reflexivity on the identified narratives. As shown in Table 1, engaged actors in the workshops were mostly experts, academics, or public servants from different administrations and governmental bodies. However, there were also farmers, water management, and civil society organisations. Therefore, the challenge was how to design and present our analysis to such a diverse plenary in a way that could challenge assumptions about the expected roles of AWR while raising interest to spark discussions.

The process was highly interdisciplinary with quantitative and qualitative researchers working in close interaction. The most representative narratives found during the previous analysis were used to create a story about the innovation and its deployment in each study area. In Gran Canaria, the script connected justification (why?), normative (what?), and explanation narratives (how?) adding a temporal flow from past/present roles or challenges of AWR to future expectations. In Tenerife, the story emphasised the existence of different justifications for the need of AWR and explored divergences with regards to the use of reclaimed water.

Each narrative was illustrated with several anonymized claims from the interviews, plus, if data pertinent to the narrative was available, one or more graphs. The selection of the graphs' format and content followed criteria of relevance and inclusiveness. That is, we chose the least amount of quantitative information in the simplest visualization format (mostly pie and bar graphs) to support the messages we wanted to convey. On some occasions, the data simply supported the narrative claims reinforcing an existing consensus (like 'the use of AWR in Southeast Gran Canaria is now larger than freshwater resources'). On other occasions, it contradicted them by pointing to the presence of ambiguities and contested perspectives (like 'farmers are in favour of AWR', the survey data showed $40 \%$ of farmers rejecting the use of AWR in the Tenerife study area). Many times, it was about clarifying issues for which no information was signaled or for which different figures were used to support 
divergent positions (like the monetary and energy costs of different water sources), therefore addressing uncertainties. In addition, we found one narrative prescribing a future scenario for which potential constraints could be quantified (we estimated the cost of pumping AWR from the coastline to rural areas situated between 700 and $1000 \mathrm{~m}$ above the sea level). Finally, there were also relevant narratives referring to issues for which we had no data available (like claims about the impacts of AWR quality on soils and crops) or depicting futures which could not be estimated with existing data (for instance the expected role of renewable energy sources to lower the price of AWR). In those cases, we included the qualitative information about the narrative, signaling the lack of data, and the associated uncertainties. Figure 2 presents a summary of these different QST strategies. In the Online Appendix, we expand on the mentioned examples for each strategy.

\section{Participatory assessment of narratives}

The last stage of our QST process (Fig. 1) was to create spaces for social interaction where narratives could be assessed and desired futures imagined. A participatory workshop was organised in each study area engaging a total of 31 actors in Gran Canaria and 34 in Tenerife (Table 1). The workshops followed a similar structure. After presenting the mixed-methods analysis of narratives and contextualizing it within the MAGIC project and QST experimental research, participants were divided into 3 working groups. A participatory narrative inquiry method adapted from Kurtz $(2014)^{2}$ was used to appraise identified narratives within the groups: one Business as usual scenario (BAU) and two Alternative scenarios (Table 2).

The alternative scenarios were designed considering the results of our previous analysis. Considering the notable consensus of AWR observed in Gran Canaria, the scenarios were framed according to identified 'what for' narratives. They mostly referred to making AWR accessible for small and rural farmer. On the other hand, alternative scenarios in Tenerife were designed to explore contestation on the justification for the development and use of reclaimed water, providing a space for under-represented narratives to be expressed. For this purpose, we used imaginary news depicting 'negative' near-future contextual changes, namely the food trade and climate-energy crisis, that could potentially influence the use of reclaimed water in the study area. Additionally, this workshop kicked off with a field trip. We visited three actors holding different perspectives and information about the reclamation project: the reclamation plant and

\footnotetext{
2 This methodology was originally adapted by StoryConnect (https:// storyconnect.nl) for a workshop on social-ecological resilience in the Water Science for Impact conference in Wageningen, October 2019.
}

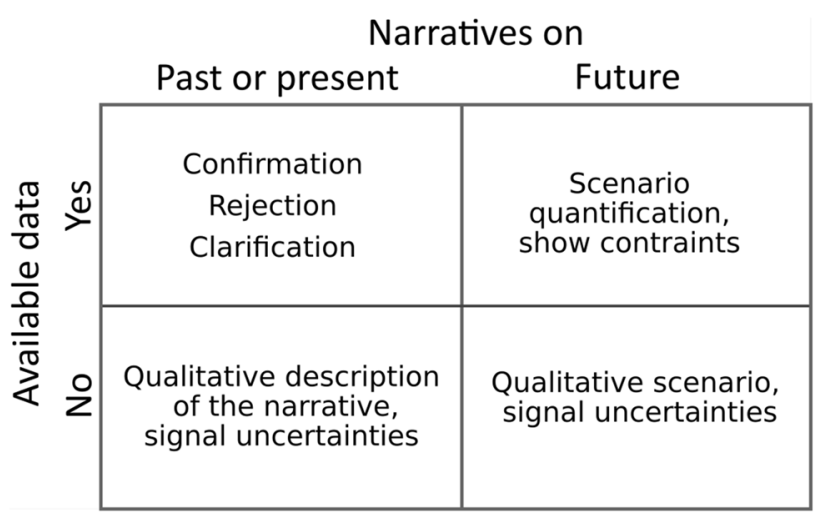

Fig. 2 Strategies for quantitative story-telling

two farmers. Thereby, narratives as 'knowing in action' were added to the pool of information to explore divergences.

Within the groups, each participant was provided with a printed booklet including the mixed qualitative and quantitative analysis of 4-5 narratives to assess. The narratives for each group were selected to prompt a discussion about the context, constraints and uncertainties of the use of AWR within each scenario. For instance for the BAU scenarios, we selected narratives referring to the contribution of AWR to groundwater conservation and to foster agricultural production to explore uncertainties in these connections. On the other hand, assessed narratives in alternative scenarios referred to accessibility factors like price, quality, and energy costs. Narratives on actual problems and impacts generated by the use of AWR were appraised by all groups.

To assess the narratives, the same iterative process was followed: first, the narrative was read and time was given to go over the data and think of their opinions; second, deliberation over the narratives was structured with a two-axes panel in which the vertical axis depicted a dimension of viability from 'Sure' to 'Impossible' and the horizontal axis depicted a dimensions of desirability from 'Great' to 'Terrible'. The resulting four-quadrant space provided a way to structure the views from participants on the different narratives according to the combination of the two plausibility criteria. The discussion was organised in rounds, so all actors could voice their opinion and locate their contributions in the panel. The aggregation of individual opinions generated a pattern that spoke for the collective positioning of the group with regards to each narrative. The process was repeated, so that, by the end of the exercise, collective patterns showing the assessment of the scenario were obtained.

Building upon this reflection, participants were asked to define a future out of the ideas within the viable-desirable quadrant using a headline format. In a final backcasting exercise, participants were asked to identify external and internal drivers for this future, to propose actions and to 
Table 2 Scenarios used for framing the participatory narrative assessment

\begin{tabular}{llll}
\hline & Business as usual & Alternative framing 1 & Alternative framing 2 \\
\hline $\begin{array}{l}\text { Southeast Gran Canaria } \\
\text { Framing }\end{array}$ & $\begin{array}{c}\text { Continuation of agricultural and } \\
\text { water governance patterns } \\
\text { Example of narrative assessed } \\
\text { "Aquifers are recovering thanks to } \\
\text { the use of AWR" }\end{array}$ & $\begin{array}{c}\text { Diversification of crops using AWR quality of AWR generates } \\
\text { impacts on soils and crops" }\end{array}$ & $\begin{array}{c}\text { Access to AWR in high rural lands } \\
\text { price of AWR" }\end{array}$ \\
$\begin{array}{l}\text { Northeast Tenerife } \\
\text { Framing }\end{array}$ & $\begin{array}{c}\text { Continuation of agricultural and } \\
\text { water governance patterns } \\
\text { "Reclaimed water is needed to stop } \\
\text { aquifer overdraft" }\end{array}$ & $\begin{array}{c}\text { Crisis of global food trade chains } \\
\text { "Price and quality of reclaimed } \\
\text { water may hamper crop exporta- } \\
\text { tion" }\end{array}$ & $\begin{array}{c}\text { Climate and energy supply crisis } \\
\text { price of AWR" }\end{array}$ \\
\hline
\end{tabular}

assign accountability by naming the actors and institutions that should be involved in those actions.

\section{Outcomes}

We introduced the QST goal of generating pluralistic and reflexive knowledge co-creation processes about complex nexus problems to enhance the quality of policy and innovation narratives dealing with such problems. This is not the place to expand on the richness of the results obtained from the above described research. Yet, from a process learning perspective, it is worth reflecting on the extent to which the QST methodological hypothesis was confirmed in our case.

Our QST process engaged a total of 75 actors holding knowledge about the three dimensions of the WEF nexus, with a particularly relevant presence of public authorities and practitioners (Table 1). Considering the technical profile of nexus practitioners (Hoolohan et al. 2018), our sample was representative of this knowledge ecosystem. However, local knowledge from farmers and civil society organisations, and women were under-represented both in the interviews and the workshops. Another drawback of the process was the low rate of continuity between the two engagement activities (only $25 \%$ of the interviewed actors shown in Table 1 participated in the workshops). Reluctancy from stakeholders to interact is rather common in controversial issues (Gray, 2004). For instance, in the Tenerife case, private freshwater owners with high stakes in local water management agreed to participate in the interviews but not in the workshop.

Workshop exercises were carefully crafted to guarantee equal opportunities to participate. However, we faced procedural difficulties like a limited capacity to deal with diversity and power asymmetries during the discussion. As a result, not all voices received the same attention or credit. For instance, opinions from the only farmer against the use of AWR in Tenerife were rapidly downplayed, or those from young university students were qualified as 'utopian' by a senior engineer from the energy sector. This is both a problem of balanced representation of different perspectives and a lack of facilitation skills required to translate between different languages within heterogeneous groups (Barnaud and Passen 2013). As Paschen and Ison (2014, p 1084) point out, 'the use of expert or lay languages can exclude or include communication actors and thus influence the kind of knowledge produced and accepted as authoritative'. Expert and technical language, initiated with our presentation of narrative analysis, dominated the interactions and created barriers to other types of expressions. Notwithstanding these limitations, pooling together different knowledge systems was effective in generating a discussion over several nexus issues associated with AWR and in addressing some epistemological and relational uncertainties. For instance, having precise information on the price and energy costs of different water sources and on the direct relation between prices and the quality of produced AWR enabled a shared understanding of constraints and helped the participatory assessment of narratives.

With regards to reflexivity, our aim in the workshops was to use narratives as vehicles for exploring normative values and assumptions underlying the promotion of AWR and, building upon such reflection, to propose further actions (Popa et al. 2015). Figure 3 presents the aggregated results obtained from the participatory assessment exercise. Without delving into the particularities of the narratives assessed, the obtained patterns show how most contributions fell within the desirable side of the panels. Constraints to desirability of the narratives were mostly expressed in the BAU discussion groups. Whereas this outcome aligns with numerous studies showing the social tendency toward positive futuristic thinking (Carlgren et al. 2016), it also supports the social acceptance of AWR revealed in our previous analysis. In fact, most of the scenarios and actions proposed in the final part of the workshops pointed to futures where AWR played a key role in either transforming agricultural 

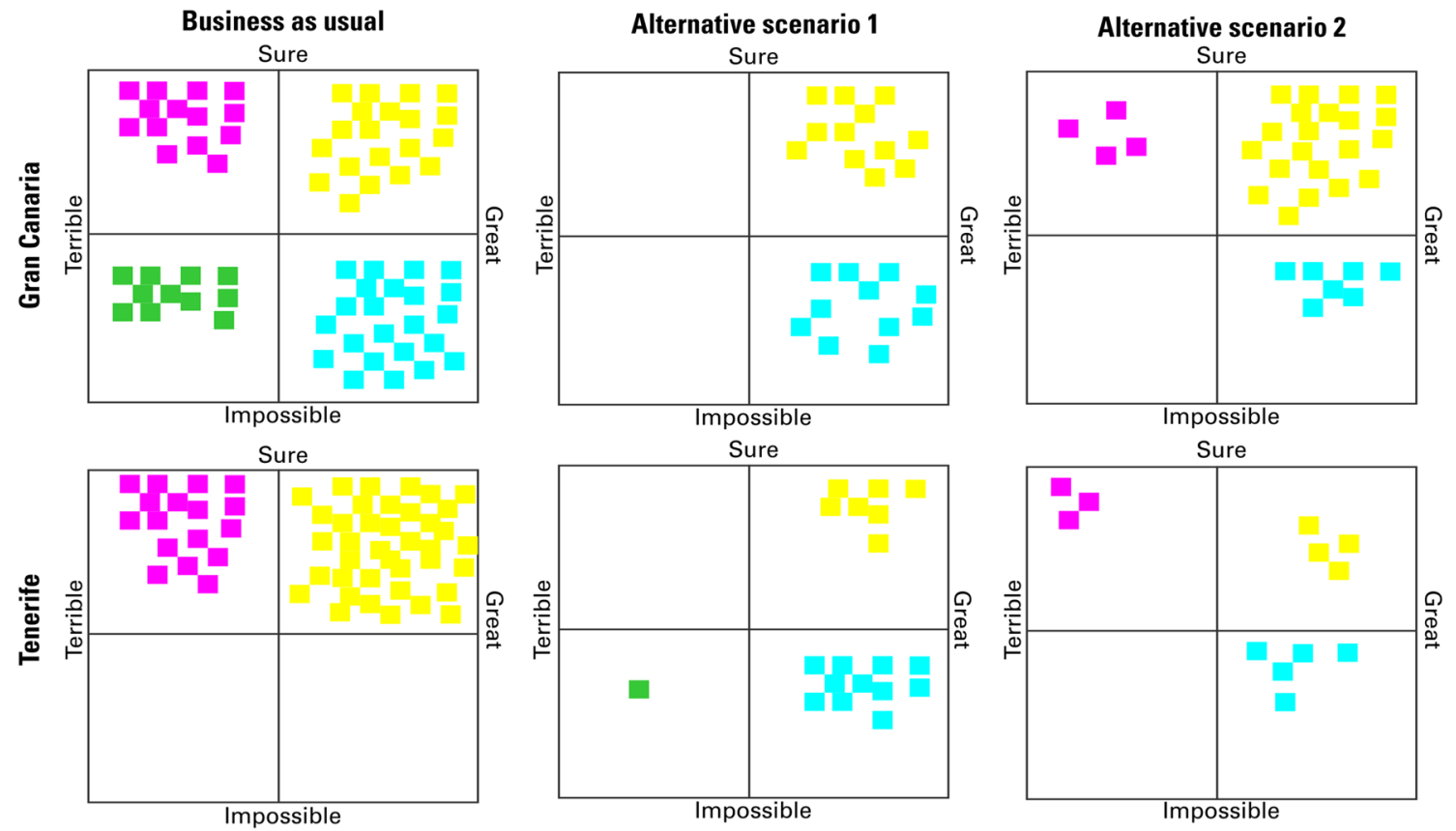

Fig. 3 Outcomes from the participatory narrative assessment in the two workshops. Each dot represents an individual opinion shared in a posit during the discussion. Colours indicate the outcome of the assessment criteria provided by each quadrant. Yellow: viable and desirable; turquoise: desirable but not viable; green: not desirable and not viable; pink: not desirable but viable) production patterns or facing the impacts of global changes. This result suggests that the mainstream support to AWR is representative of wider meta-narratives and socio-technical imaginaries in the Canaries (Paschen and Ison 2014; Jassanoff and Kim 2015).

On the other hand, viability constraints were signaled in all alternative scenarios and, especially, in the BAU of Gran Canaria. This result speaks for the different stage of implementation of AWR in Gran Canaria, where the long-term use of AWR has yielded problems and learnings, and in Tenerife, where AWR fall in the very initial stages of the expectation curve for innovations (Borup et al. 2006). Expressed constraints to viability enabled a more nuanced analysis of explanation narratives (how to make AWR accessible?), of the relations between different drivers of water scarcity and of those with the expected benefits of these innovations.

Altogether, our reflexivity exercise enabled a comprehensive assessment of constraints and trade-offs between the different roles of AWR. Building upon this knowledge, new narratives were co-created, tying actions to specific actors in desirable and viable pathways. However, our capacity to unsettle assumptions underlying AWR as techno-fixes to water scarcity was limited. Our attempts to bring up narratives contesting these innovations were not amplified by attendants whose interests gathered around the discussion of who is AWR for, and under what circumstances. These outcomes feedback on the QST goal of challenging dominant innovation narratives (Strand et al. 2018) by suggesting that the focus on quality of narratives should be process oriented instead of outcome oriented. In line with Strand (2019), we argue that a more humble strategy of worthwhile collaboration on co-narrating desired socio-technical pathways may yield transformative social learning and indirectly induce policy changes. ${ }^{3}$

\section{Concluding remarks}

The QST process has the potential to help enact processes of progressive policy change that recognize crucial sustainability challenges illuminated by the WEF nexus concept (Matthews et al. 2019). QST proposes the mix of narrative analysis and nexus accounting in interaction with a plurality of knowledge holders. Thereby, QST advances both inter and transdisciplinary efforts in WEF nexus and sustainability research (Hoolohan et al. 2018; Howarth and Monasterolo 2017). On one hand, the proposed mixedmethods approach is particularly well suited for linking socio-cultural and biophysical dimensions of sustainability challenges (Paschen and Ison 2014). On the other hand,

\footnotetext{
3 The results from our workshops have been considered for new agricultural policies by the regional government of the Canary Islands and for new guidelines on the assessment of reclaimed water projects by the national Spanish Ministry for Ecological Transition.
} 
QST mobilizes knowledge from scientists and practitioners 'bridging competing narratives of sustainability in a process that challenges the dominance of techno-science' (Bremer and Funtowicz 2015). By opening spaces for reflexivity on the effectiveness of technological solutions where different narratives can learn from each other, QST offers a systemic approach to navigate wicked sustainability problems toward adaptive multi-resource governance (Ison et al. 2016; Luederitz et al. 2017).

This paper presents one of many possible leaps from theory to practice of QST analyzing the role of AWR as innovations to face water scarcity in the Canary Islands. We collaboratively designed and tested a full methodological proposal for operationalizing QST in a situated co-creation fashion that conceives narratives not only as static discourses in policy text, but as dynamic, constantly rewiring, social meaning-making (Paschen and Ison, 2014). Our interdisciplinary collaboration enriched the process in terms of analytical power and capacity to understand and embrace different perspectives about the problem. However, as highlighted in other studies (Norström et al. 2020), coordination efforts were intense in terms of the alignment of skills and negotiation of key decisions.

Concerning the applied methods, we introduced quantitative analysis of nexus networks within wider social science-driven qualitative narrative inquiry (Albrecth et al. 2018). Far from close scenario predictions, the function of numeric analysis within QST is understood as that of providing pertinent feedback to narratives in terms of tradeoffs and biophysical constraints across nexus dimensions, while signaling epistemological and relational uncertainties (Brugnach et al. 2008). This mixed information was used as fuel for social interactions in participatory settings where new knowledge and narratives on desired socio-technical pathways were co-created. From a procedural perspective, we strived and partially succeeded in applying principles of pluralism and reflexivity to our process (Noström et al. 2020; Popa et al. 2015). Open questions remain as to how to effectively mobilize radically diverse knowledge and value systems in complex analytical exercises where everyone feels safe to participate (Barnaud and Paussen 2013).

Supplementary Information The online version contains supplementary material available at https://doi.org/10.1007/s11625-021-00933-y.

Acknowledgements We would like to acknowledge the European H2020 project entitled Moving Towards Adaptive Governance in Complexity (MAGIC GA-, June 2016-Sep 2020). This project has received funding from the European Union's Horizon 2020 Research and Innovation Programme under grant agreement No. 689669. The authors thank Adrián Monterrey for his technical contribution in the interviews and field surveys. The present work reflects only the authors' view and the funding Agency cannot be held responsible for any use that may be made of the information it contains. The authors express their gratitude to the ITC and the citizen centre of Tejina for facilitating the spaces for deliberation and to all the persons who selflessly participated both in the interviews and the workshops.

Open Access This article is licensed under a Creative Commons Attribution 4.0 International License, which permits use, sharing, adaptation, distribution and reproduction in any medium or format, as long as you give appropriate credit to the original author(s) and the source, provide a link to the Creative Commons licence, and indicate if changes were made. The images or other third party material in this article are included in the article's Creative Commons licence, unless indicated otherwise in a credit line to the material. If material is not included in the article's Creative Commons licence and your intended use is not permitted by statutory regulation or exceeds the permitted use, you will need to obtain permission directly from the copyright holder. To view a copy of this licence, visit http://creativecommons.org/licenses/by/4.0/.

\section{References}

Albrecht TR, Crootof A, Scott CA (2018) the water-energy-food nexus: a systematic review of methods for nexus assessment. Environ Res Lett 13(4):043002

Barnaud C, Van Paassen A (2013) Equity, power games, and legitimacy: dilemmas of participatory natural resource management. Ecology and Soci 18(2):21.http://dx.doi.org/10.5751/ ES-05459-180221

Borup M, Brown N, Konrad K, Van Lente H (2006) The sociology of expectations in science and technology. Technol Anal Strateg Manag 18:285-298. https://doi.org/10.1080/09537320600777002

Bremer S, Funtowicz S (2015) Negotiating a place for sustainability science: narratives from the Waikaraka Estuary in New Zealand. Environ Sci Policy 53:47-59

Bremer S, Blanchard A, Mamnun N, Stiller-Reeve M, Haque MM, Tvinnereim E (2017) Narrative as a method for eliciting tacit knowledge of climate variability in Bangladesh. Weather Clim Soc 9(4):669-686

Brugnach M, Dewulf A, Pahl-Wostl C, Taillieu T (2008) Toward a relational concept of uncertainty: about knowing too little, knowing too differently, and accepting not to know. Ecol Soc. https://doi. org/10.5751/ES-02616-130230

Cabello Villarejo V, Musicki Savic A, Romero Manrique D, Monterrey Viña A, Guimarães Pereira Â, Peñate Suárez B (2020) Solving water problems vs. creating new ones: the use of alternative water resources for irrigation MAGIC (H2020-GA 689669). In: Project Deliverable 6.7.

Cabello V, Kovacic Z, Van Cauwenbergh N (2018) Unravelling narratives of water management: reflections on epistemic uncertainty in the first cycle of implementation of the Water Framework Directive in southern Spain. Environ Sci Policy 85:19-27. https://doi. org/10.1016/j.envsci.2018.03.019

Cabello V, Renner A, Giampietro M (2019) Relational analysis of the resource nexus in arid land crop production. Adv Water Resour 130:258-269. https://doi.org/10.1016/j.advwatres.2019.06.014

Carlgren L, Rauth I, Elmquist M (2016) Framing design thinking: The concept in idea and enactment. Creat Innov Manag 25(1):38-57

Cash DW, Clark WC, Alcock F, Dickson NM, Eckley N, Guston DH, Mitchell RB (2003) Knowledge systems for sustainable development. Proc Natl Acad Sci 100(14):8086-8091

Corral-Quintana S, Legna-de la Nuez D, Verna CL, Hernández JH, de Lara DRM (2016) How to improve strategic decision-making in complex systems when only qualitative information is available. Land Use Policy 50:83-101 
Felt U, Kommission E (eds) (2007) Taking European knowledge society seriously: report of the Expert Group on Science and Governance to the Science, Economy and Society Directorate, Directorate-General for Research, European Commission, EUR. Off. for Official Publ. of the Europ. Communities

Funtowicz SO, Ravetz JR (1993) Science for the post-normal age. Futures 25:739-755. 10.1016/0016-3287(93)90022-L

Giampietro M, Bukkens SGF (2014) The multi-scale integrated analysis of societal and ecosystem metabolism. In: Giampietro M, Aspinall RJ, Ramos-Martin J, Bukkens SGF (eds) Resource accounting for sustainability assessment: the nexus between energy, food, water and land use, routledge explorations in sustainability and governance. Routledge, New York, pp 11-21

Gray B (2004) Strong opposition: frame-based resistance to collaboration. J Community Appl Soc Psychol 14(3):166-176

Gude VG (2017) Desalination and water reuse to address global water scarcity. Rev Environ Sci Bio/Technol 16(4):591-609

Harwood SA (2018) In search of a (WEF) nexus approach. Environ Sci Policy 83:79-85. https://doi.org/10.1016/j.envsci.2018.01.020

Hajer MA (1995) The politics of environmental discourse: ecological modernization and the policy process. Clarendon Press, Oxford University Press

Healy S (1999) Extended peer communities and the ascendance of post-normal politics. Futures 31:655-669. https://doi.org/10.1016/ S0016-3287(99)00025-7

Hogeboom RJ, de Bruin D, Schyns JF, Krol MS, Hoekstra AY (2020) Capping Human Water Footprints in the World's River Basins. Earths Future. https://doi.org/10.1029/2019EF001363

Hoolohan C, Larkin A, McLachlan C, Falconer R, Soutar I, Suckling J, Varga L, Haltas I, Druckman A, Lumbroso D, Scott M, Gilmour D, Ledbetter R, McGrane S, Mitchell C, Yu D (2018) Engaging stakeholders in research to address water-energy-food (WEF) nexus challenges. Sustain Sci 13:1415-1426. https://doi.org/10. 1007/s11625-018-0552-7

Howarth C, Monasterolo I (2017) Opportunities for knowledge coproduction across the energy-food-water nexus: Making interdisciplinary approaches work for better climate decision making. Environ Sci Policy 75:103-110

Jones E, Qadir M, van Vliet MT, Smakhtin V, Kang SM (2019) The state of desalination and brine production: A global outlook. Sci Total Environ 657:1343-1356

Jasanoff S, Kim SH (2015) Dreamscapes of modernity. University of Chicago Press

Jasanoff S, Markle GE, Peterson JC, Pinch T (eds) (2001) Handbook of science and technology studies. Sage publications

Kovacic Z, Di Felice LJ (2019) Complexity, uncertainty and ambiguity: Implications for European Union energy governance. Energy. Res. Soc. Sci 53:159-169. 10.1016/j.erss.2019.03.005

Kurtz CF (2014) Working with stories in your community or organization: participatory narrative inquiry, 3rd edn. Kurtz-Fernhout Publishing

Luederitz C, Abson DJ, Audet R, Lang DJ (2017) Many pathways toward sustainability: not conflict but co-learning between transition narratives. Sustain Sci 12(3):393-407

Marschütz B, Bremer S, Runhaar H, Hegger D, Mees H, Vervoort J, Wardekker A (2020) Local narratives of change as an entry point for building urban climate resilience. Clim Risk Manag 28:100223. https://doi.org/10.1016/j.crm.2020.100223

Matthews KB, Blackstock KL, Rivington M, Waylen K, Miller DG, Wardell-Johnson D, Giampietro M (2017) Delivering more than the "Sum of the Parts": using Quantitative Storytelling to address the challenges of conducting science for policy in the EU land, water and energy nexus. In: 22nd International Congress on Modelling and Simulation, Hobart, Tasmania, Australia (Vol. 3)

Matthews KB, Waylen KA, Blackstock KL, Juarez-Bourke A, Millera DG, Wardell-Johnson DH, Giampietro M (2019) Science for sustainability: using societal metabolism analysis to check the robustness of european union policy narratives in the water, energy and food nexus. In: 23rd International Congress on modelling and simulation, Canberra, ACT, Australia, 1 to 6 December 2019.

McEvoy J, Wilder M (2012) Discourse and desalination: potential impacts of proposed climate change adaptation interventions in the Arizona-Sonora border region. Glob Environ Chan Add Insult Injury 22:353-363. https://doi.org/10.1016/j.gloenvcha.2011.11. 001

Molle F (2008) Nirvana concepts, narratives and policy models: insights from the water sector. Water Altern 1:131-156

Monterrey-Viña A, Musicki-Savic A, Díaz-Peña FJ, Peñate-Suárez B (2020) Technical and agronomical assessment of the use of desalinated seawater for coastal irrigation in an insular context. Water 12:272. https://doi.org/10.3390/w12010272

Mohtar RH, Daher B (2016) Water-energy-food nexus framework for facilitating multi-stakeholder dialogue. Water Int 41(5):655-661

Norström AV, Cvitanovic C, Löf MF, West S, Wyborn C, Balvanera P, Bednarek AT, Bennett EM, Biggs R, de Bremond A, Campbell BM, Canadell JG, Carpenter SR, Folke C, Fulton EA, Gaffney O, Gelcich S, Jouffray J-B, Leach M, Tissier ML, Martín-López B, Louder E, Loutre M-F, Meadow AM, Nagendra H, Payne D, Peterson GD, Reyers B, Scholes R, Speranza CI, Spierenburg M, Stafford-Smith M, Tengö M, van der Hel S, van Putten I, Österblom H (2020) Principles for knowledge co-production in sustainability research. Nat Sustain. https://doi.org/10.1038/ s41893-019-0448-2

Pahl-Wostl C (2019) Governance of the water-energy-food security nexus: a multi-level coordination challenge. Environ Sci Policy 92:356-367

Paschen J-A, Ison R (2014) Narrative research in climate change adaptation-exploring a complementary paradigm for research and governance. Res Policy 43:1083-1092. https://doi.org/10.1016/j. respol.2013.12.006

Popa F, Guillermin M, Dedeurwaerdere T (2015) A pragmatist approach to transdisciplinarity in sustainability research: From complex systems theory to reflexive science. Futures Adv Transdiscipl 2004-2014 65:45-56. https://doi.org/10.1016/j.futures. 2014.02.002

Renner A, Giampietro M (2020) Socio-technical discourses of European electricity decarbonization: Contesting narrative credibility and legitimacy with quantitative story-telling. Energy Res Soc Sci 59:101279. https://doi.org/10.1016/j.erss.2019.101279

Rittel HWJ, Webber MM (1973) Dilemmas in a general theory of planning. Policy Sci 4:155-169

Saltelli A, Giampietro M (2017) The fallacy of evidence based policy. Futures 91:62-71. https://doi.org/10.1016/j.futures.2016.11.012

Serrano-Tovar T, Peñate Suárez B, Musicki A, de la Fuente Bencomo JA, Cabello V, Giampietro M (2019) Structuring an integrated water-energy-food nexus assessment of a local wind energy desalination system for irrigation. Sci Total Environ 689:945-957. https://doi.org/10.1016/j.scitotenv.2019.06.422

Stephan RM, Mohtar RH, Daher B, Irujo AE, Hillers A, Ganter JC, Karlberg L, Martin L, Nairizi S, Rodriguez DJ, Sarni W (2018) Water-energy-food nexus: a platform for implementing the Sustainable Development Goals. Water. Int 43:472-479.https://doi. org/10.1080/02508060.2018.1446581

Strand R, Saltelli A, Giampietro M, Rommetveit K, Funtowicz S (2018) New narratives for innovation. J Clean Prod 197:1849-1853. https://doi.org/10.1016/j.jclepro.2016.10.194

Strand R (2019) Striving for Reflexive Science. Fteval J Res Technol Policy Eval Issue 48:56-61. https://doi.org/10.22163/fteval.2019. 368 
Venghaus S, Hake J-F (2018) Nexus thinking in current EU policiesThe interdependencies among food, energy and water resources. Environ Sci Policy. https://doi.org/10.1016/j.envsci.2017.12.014

Von Medeazza GM (2005) "Direct" and socially-induced environmental impacts of desalination. Desalination 185(1-3):57-70

Voelker T, Blackstock K, Kovacic Z, Sindt J, Strand R, Waylen K (2019) The role of metrics in the governance of the water-energyfood nexus within the European Commission. J Rural Stud. https:// doi.org/10.1016/j.jrurstud.2019.08.001
Zhang C, Chen X, Li Y, Ding W, Fu G (2018) Water-energy-food nexus: Concepts, questions and methodologies. J Clean Prod 195:625-639. https://doi.org/10.1016/j.jclepro.2018.05.194

Publisher's Note Springer Nature remains neutral with regard to jurisdictional claims in published maps and institutional affiliations. 